\title{
Processing and in vitro Degradation of Starch/EVOH Thermoplastic Blends*
}

\author{
Rui L. Reis, ${ }^{1,2}+$ Sandra C. Mendes, ${ }^{2,3}$ António M. Cunha ${ }^{3}$ \& Michael J. Bevis ${ }^{4}$ \\ ${ }^{1}$ Department of Metallurgical Engineering, University of Porto, FEUP, Rua dos Bragas, 4099 Porto Codex, Portugal \\ ${ }^{2}$ INEB - Institute for Biomedical Engineering, Praça Coronel Pacheco 1, 4050 Porto, Portugal \\ ${ }^{3}$ Department of Polymer Engineering, University of Minho, Campus de Azurém, 4800 Guimarães, Portugal \\ ${ }^{4}$ Wolfson Centre for Materials Processing, Brunel University, Uxbridge, Middlesex UB8 3PH, UK
}

(Received 30 September 1996; revised version received 25 November 1996; accepted 20 December 1996)

\begin{abstract}
This paper describes the processing dependence of the mechanical properties of three blends of starch/ethylene vinyl alcohol (EVOH) with potential uses as biomaterials. These blends exhibit a distinct rheological behaviour and mechanical performance. Using shear controlled orientation in injection moulding (Scorim) it was possible to induce anisotropy into the mouldings and to simultaneously enhance stiffness and ductility. Degradation was studied in simulated physiological solutions (Hank's balanced salt solution) with and without added bovine serum. Both the dry weight loss and the changes in mechanical properties were determined for ageing periods up to 80 days. The degradation behaviour proved to be strongly dependent on the formulation of the material studied, and on the addition of proteins. The susceptibility of the starch/EVOH blends to degradation when sterilised with ethylene oxide (EtO) was also studied, and showed that the polymers could stand one EtO sterilisation cycle. However, two consecutive cycles severely degraded the polymer structure and properties.
\end{abstract}

Polym. Int. 43, 347-352 (1997)

No. of Figures: 9 No. of Tables: 5 No. of References: 18

Key words: biodegradable polymers, processing, degradation, biomaterials, sterilisation.

\section{INTRODUCTION}

Biodegradable polymers may be useful in biomedical applications, for temporary hard and soft tissue replacements. ${ }^{1-3}$ A polymer used in this type of application must exhibit adequate mechanical properties coupled with controlled degradation rates in the presence of human body fluids. ${ }^{1}$ Bone plates, screws and sutures are well known examples of current uses of biodegradable polymers in medicine. ${ }^{1,4,5}$ The more widely used systems are based on polylactic acid (PLA) ${ }^{1-3}$ polyglycolic acid $(\mathrm{PGA})^{2}$ and their copolymers and poly-

\footnotetext{
* Presented at 'The Cambridge Polymer Conference: Partnership in Polymers', Cambridge, UK, 30 September-2 October 1996.
}

$\dagger$ To whom all correspondence should be addressed. hydroxybutyrate (PHB). ${ }^{1,4}$ However, it has not yet been possible to develop materials that combine the required mechanical properties and suitable degradation behaviour. Additionally, the possibility of inducing anisotropy into the mouldings, in order to reproduce the properties of natural tissues, has not been fully explored.

Blends of native corn starch (constituted from amylose and amylopectin) with ethylene vinyl alcohol $(\mathrm{EVOH})$ are potential alternatives to the polymers currently used in clinical applications. ${ }^{6,7}$ These blends will be referred to as SEVA. They are commercially produced by Novamont (Italy) under the tradename Mater-Bi, exhibit thermoplastic behaviour, and respond to standard melt-processing methods. This class of materials has been reported as being biodegradable, ${ }^{8-12}$ but has only very recently been proposed for possible use as biomaterials. $^{6,7}$ 
This paper describes the processing of SEVA blends and relates the injection-moulding parameters to the attained mechanical performance. Furthermore, the polymer degradation was studied in simulated physiological solutions, with and without added proteins. The overall goal of the research is to develop better engineered materials for temporary tissue replacement.

\section{MATERIALS AND METHODS}

The materials studied were blends of corn starch with EVOH copolymers $(40 / 60 \mathrm{~mol} / \mathrm{mol})$, obtained from Novamont, Italy. Several grades of SEVA, with different molecular weights and quite distinct rheological behaviours, as assessed by melt flow index (MFI) measurements and flow curves obtained in capillary rheometric experiments, ${ }^{6,11}$ were chosen for the study. The selected grades will be referred to as SEVA-A (tradename Mater-Bi SAO31), SEVA-B (Mater-Bi AIO5H) and SEVA-C (Mater-Bi 1128RR), with the respective molecular weights increasing from $A$ to $C$.

Further details on the production and characteristics of the materials studied may be found in works by Bastioli et al. ${ }^{8,10,11}$ An extensive characterisation of these materials, which focuses on their potential for use as biomaterials, has recently been published. ${ }^{6}$

Samples of SEVA were injection-moulded either (i) conventionally or (ii) using the shear controlled orientation injection moulding (Scorim) technique. ${ }^{13-16}$ The latter technique is based on the action of a macroscopic shear field imposed on the polymer at the melt/solid interface during solidification. This effect is realised by the use of a Scorim device, fitted between the injection screw/barrel and the mould cavity, which incorporates two oscillating hydraulic pistons that, when activated out of phase, provide for the introduction of anisotropy into the moulded samples. The final result is the control of morphology, namely the orientation of the macromolecules and/or filler constituents within the moulded part.

Two types of circular cross-section mouldings have been produced, having two different diameters, 1.5 and $5.0 \mathrm{~mm}$; they will be respectively designated as $\phi 1.5$ and $\phi 5$. The conventional samples $(\phi 1 \cdot 5$, in order to induce a high orientation level into the mouldings) were moulded on a standard injection machine (KlocknerFerromatik Desma FM20). The Scorim samples $(\phi 5)$ were injection-moulded using a Demag D-150 NCIII-K machine fitted with a Scorim device. This equipment was used to produce both conventional and Scorim $\phi 5$ mouldings. The processing conditions used, respectively, for conventional and Scorim injection-moulding are presented in Tables 1 and 2.

The influence of the processing conditions on the mechanical behaviour of the injection-moulded parts was studied by means of tensile testing. These tests were
TABLE 1. Processing conditions for conventional injection moulding

\begin{tabular}{lccccc}
\hline Material & $\begin{array}{c}T_{\text {inj }} \\
\left({ }^{\circ} \mathrm{C}\right)\end{array}$ & $\begin{array}{c}T_{\text {mould }} \\
\left({ }^{\circ} \mathrm{C}\right)\end{array}$ & $\begin{array}{c}\text { Flow rate } \\
\left(\mathrm{cm}^{3} \mathrm{~s}^{-1}\right)\end{array}$ & $\begin{array}{c}P_{\text {hold }} \\
(\mathrm{MPa})\end{array}$ & $\begin{array}{c}\text { Cycle } \\
\text { time }(\mathrm{s})\end{array}$ \\
\hline SEVA-A & 175 & 60 & 130 & 40 & 30 \\
SEVA-B & 180 & 60 & 180 & 50 & 35 \\
SEVA-C & 185 & 60 & 180 & 50 & 35 \\
\hline
\end{tabular}

used to determine the ultimate tensile strength (UTS), the secant modulus at $1 \%$ strain $\left(E_{1 \%}\right)$ and the strain at break $\left(\varepsilon_{\mathrm{r}}\right)$. The tensile tests were performed on an Instron 4505 universal mechanical testing machine, fitted with a resistive extensometer (gauge length $10 \mathrm{~mm})$, in a controlled environment $\left(23^{\circ} \mathrm{C}\right.$ and $55 \%$ relative humidity (r.h.)). The cross-head speed was $5 \mathrm{~mm} \mathrm{~min}^{-1}\left(8.3 \times 10^{-5} \mathrm{~m} \mathrm{~s}^{-1}\right)$ until $1 \%$ strain, and was then increased to $50 \mathrm{~mm} \mathrm{~min}^{-1}\left(8.3 \times 10^{-4} \mathrm{~m} \mathrm{~s}^{-1}\right)$ until fracture. The mouldings were stored under controlled temperature and moisture conditions prior to testing. Fracture surfaces were observed by scanning electron microscopy (SEM) using Leica Cambridge S360 and Jeol JSM 35-C instruments.

The environments to which the materials studied were exposed for the purpose of evaluating the materials' degradation were as follows. Samples were immersed for several pre-fixed ageing periods in a simulated physiological solution (HBSS, Hank's balanced salt solution, Gibco 041-04025M, from Life Technologies, Paisley, UK) at $37^{\circ} \mathrm{C}$. In some tests, 10 or $30 \%$ $(\mathrm{v} / \mathrm{v})$ of a bovine serum solution (Sigma C-6278, St. Louis, USA) was added to the HBSS. After being removed from the solution, one batch of samples was dried in an oven for $48 \mathrm{~h}$ at $70^{\circ} \mathrm{C}$ in order to determine the respective dry weight loss. The other batch of samples was stored in a room with controlled atmosphere $\left(23^{\circ} \mathrm{C}, 55 \%\right.$ r.h.) for two weeks, in order to stabilise the moisture content. Then, these samples were tensile tested, as described above, in order to evaluate the changes in mechanical properties as a function of the ageing time. The degraded samples were further characterised by Raman and Fourier transform infrared (FTIR) spectroscopies.

TABLE 2. Processing conditions for Scorim moulding $^{a}$

\begin{tabular}{cccccc}
\hline Condition & $\begin{array}{c}T_{\text {inj }} \\
\left({ }^{\circ} \mathrm{C}\right)\end{array}$ & $\begin{array}{c}T_{\text {mould }} \\
\left({ }^{\circ} \mathrm{C}\right)\end{array}$ & $\begin{array}{c}P_{\text {hold }} \\
(\mathrm{MPa})\end{array}$ & $\begin{array}{c}\text { Scorim } \\
\text { time }(\mathrm{s})\end{array}$ & $\begin{array}{r}P_{\text {max }} \\
(\mathrm{MPa})\end{array}$ \\
\hline Conventional & 170 & 60 & 50 & - & 150 \\
S1 & 170 & 60 & 2 & 30 & 77 \\
S2 & 170 & 60 & 13 & 40 & 211 \\
S3 & 170 & 60 & 13 & 40 & 290 \\
\hline
\end{tabular}

${ }^{a}$ All with the Scorim pistons oscillating out of phase. 
Finally, the changes introduced by autoclave sterilisation in a $12 / 88(\mathrm{v} / \mathrm{v})$ mixture of ethylene oxide $(\mathrm{EtO})$ and carbon dioxide $\left(\mathrm{CO}_{2}\right)$ were studied. Typical sterilisation conditions were a working temperature of $45^{\circ} \mathrm{C}$, a moisture level of $50 \%$, a cycle time of $14 \mathrm{~h}$ and a chamber pressure of $50 \mathrm{kPa}$. The effect of the number of sterilisation cycles was also assessed. In this case, the loss of mechanical strength and the polymer structural changes were evaluated by tensile tests and by Raman and FTIR spectroscopies, respectively.

\section{RESULTS AND DISCUSSION}

The mechanical properties of the SEVA grades proved to be strongly dependent on the rheological behaviour of the materials. The stiffness (estimated by the secant modulus at $1 \%$ of strain) changed from $0.67 \mathrm{GPa}$ (SEVA-A) to 1.17 (SEVA-B) and to $1.95 \mathrm{GPa}$ (SEVA-C), as reported in Table 3. These results should be compared with those previously published, ${ }^{6,7}$ for ISO standard samples, which did not exhibit significant orientation effects. A discussion on the influence of orientation on the properties of unreinforced and hydroxylapatite reinforced starch/EVOH blends may be found elsewhere. ${ }^{17}$

By using the Scorim process it was possible to increase the modulus to $2.97 \mathrm{GPa}$ (Table 4) with a simultaneous important enhancement of ductility, compared with the conventionally moulded samples with the same geometry. As expected, the higher packing pressures tend to increase the modulus, and the more moderate pressures lead to higher values of the strain at

TABLE 3. Mechanical properties of the three SEVA grades when conventionally injection-moulded ( $\phi 1.5 \mathrm{~mm}$ samples)

\begin{tabular}{lcccr}
\hline Material & $\begin{array}{c}\mathrm{MFI}^{a} \\
(\mathrm{~g} / 600 \mathrm{~s})\end{array}$ & $\begin{array}{c}E_{1 \%} \\
(\mathrm{GPa})\end{array}$ & $\begin{array}{c}\text { UTS } \\
(\mathrm{MPa})\end{array}$ & \multicolumn{1}{c}{$\begin{array}{c}\boldsymbol{\varepsilon}_{\mathrm{r}} \\
(\%)\end{array}$} \\
\hline SEVA-A & 19.3 & 0.67 & 25.6 & 71.9 \\
SEVA-B & 2.6 & 1.17 & 28.4 & 58.1 \\
SEVA-C & 0.7 & 1.95 & 34.9 & 142.6
\end{tabular}

${ }^{a}$ Melt flow indices, determined at $170^{\circ} \mathrm{C}$ using a load of $49 \mathrm{~N}$.

TABLE 4. Mechanical properties of SEVA-C when Scorim injection-moulded ( $\phi 5 \mathrm{~mm}$ samples)

\begin{tabular}{cccr}
\hline Condition & $\begin{array}{c}E_{1 \%} \\
(\mathrm{GPa})\end{array}$ & $\begin{array}{c}\text { UTS } \\
(\mathrm{MPa})\end{array}$ & $\begin{array}{c}\boldsymbol{\varepsilon}_{\mathrm{r}} \\
(\%)\end{array}$ \\
\hline Conventional & 1.52 & 34.1 & 22.4 \\
S1 & 2.30 & 35.2 & 48.3 \\
S2 & 2.02 & 38.9 & 35.8 \\
S3 & 2.97 & 41.8 & $7 \cdot 1$ \\
\hline
\end{tabular}

break. In fact, the application of the Scorim technology proved to be effective in increasing the stiffness and strength of the mouldings, without loss of ductility, for a range of polymeric systems, ${ }^{7,15-17}$ including several starch-containing blends ${ }^{7}$ and composites. ${ }^{17}$ In all cases, the mechanical performance attained was strongly dependent on the Scorim processing conditions, as confirmed by the results obtained in the present work.

Degradation was also dependent on the polymer grade (Fig. 1), being reduced for the lower MFI materials. In all cases, two degradation stages were noticeable. The first corresponds to the loss of plasticiser and the second to the breakdown of molecular chains with the consequent loss of material to the solution. After the first few days, during which the release of plasticiser is the main occurrence, there is a period without any significant loss of weight (between 4 and 14 days). This is attributed to the random breakdown of accessible covalent bonds. After this period (at about 50 days for SEVA-C and SEVA-B and 30 days of SEVA-A) the low molecular weight chains begin to leach into the solution, being responsible for the observed loss in weight. During the later stages of the test period there is a decrease in the degradation rate, which is attributed to the start of the attack on the amylose-EVOH complex, which has been reported as being much less susceptible to degradation. ${ }^{18}$

For instance, the modulus of SEVA-C (Fig. 2) was substantially decreased in the first stages ( 2 to 4 days) of degradation, on average from 1.95 to $1.52 \mathrm{GPa}$, and then degradation proceeded more slowly. The average modulus after 30 days of degradation was approximately $1.38 \mathrm{GPa}$. In contrast, the materials SEVA-B and SEVA-A exhibited an initial increase in modulus and only then did the polymers begin to show a decrease in stiffness. This is attributed to the greater plasticiser contents in these blends, being released on the first stage of the degradation and resulting in an increase in the modulus. Subsequently, the blends begin to be subjected to hydrolytic degradation and the modulus is gradually decreased. At approximately 30 days, the modulus loss for SEVA-C appears to stabilise, whereas SEVA-A and SEVA-B continue to degrade.

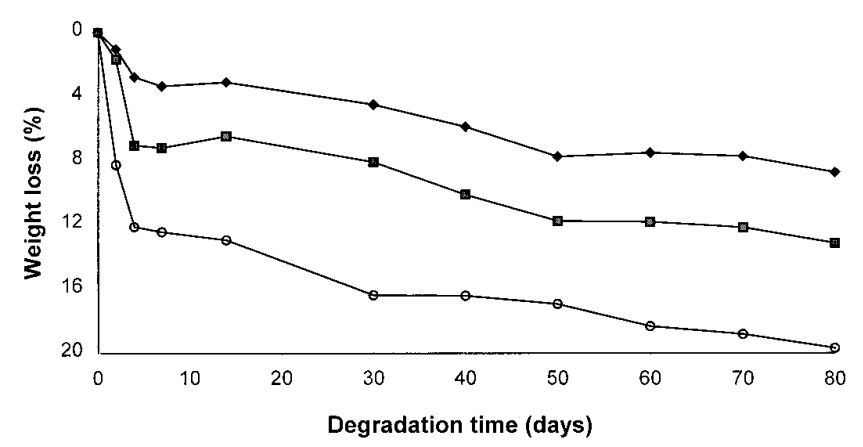

Fig. 1. Dry weight loss of (O) SEVA-A, (ם) SEVA-B and ( $\bullet$ SEVA-C, as a function of the immersion time in HBSS. 


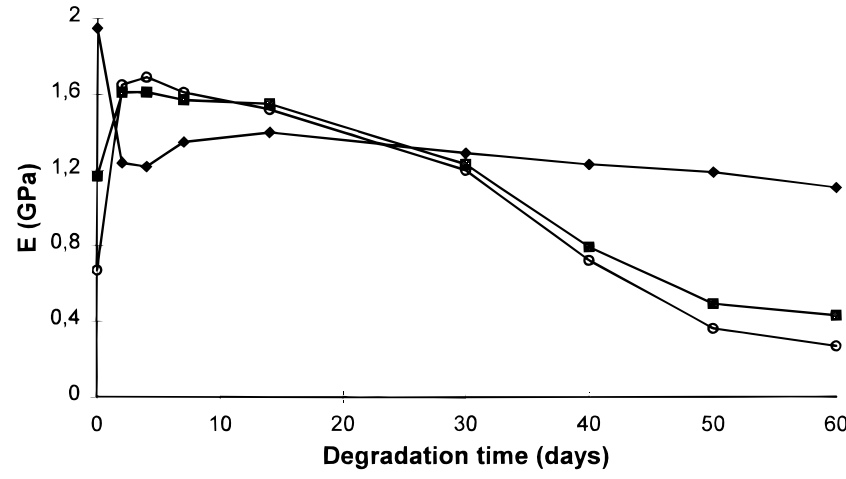

Fig. 2. Degradation of the modulus of (O) SEVA-A, SEVA-B and $(\diamond)$ SEVA-C, as a function of the immersion time in HBSS.

The loss of ductility as a function of the degradation time, evaluated by the change in strain at break with the ageing time in HBSS, is plotted in Fig. 3. For all blends, the strain at break decreased rapidly in the first few days of degradation. This initial loss of ductility is particularly noticeable in the highly oriented high molecular weight SEVA-C, in which the initial release of the smaller amounts of plasticiser to the solution induces a much more brittle behaviour. All the blends exhibit a similar trend with time, but owing to its lower degradation rate SEVA-C shows the greater strain at break at any degradation time.

Figure 4 shows typical stress versus strain curves for SEVA-C and SEVA-B, before any degradation (as-processed) and after 60 days of degradation in HBSS. For both blends, it is evident that there is a simultaneous loss of strength (decrease of UTS), stiffness (decrease of the modulus) and ductility (decrease of both the strain at break and area under the stress versus strain curve). It should be noted here that, even after 60 days of ageing, SEVA-C exhibits a higher UTS, $E_{1 \%}$ and $\varepsilon_{\mathrm{r}}$ than the as-processed SEVA-B.

The addition of bovine serum (BS) to the HBSS leads to accelerated degradation of SEVA-C and SEVA-B (Figs 5 and 6). The influence of the concentration of BS $(10$ and $30 \% \mathrm{v} / \mathrm{v})$ on the degradation of SEVA-C was

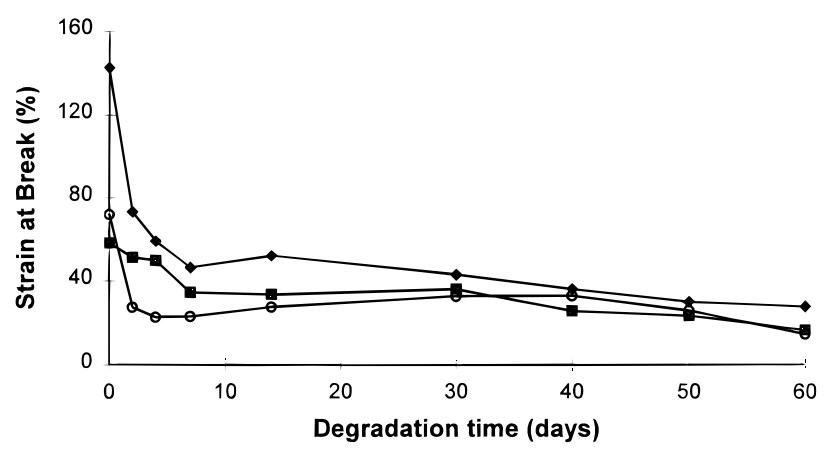

Fig. 3. Degradation of the strain at break (\%) of $(\bigcirc)$ SEVA-A, $(\square)$ SEVA-B and $(\diamond)$ SEVA-C, as a function of the immersion time in HBSS

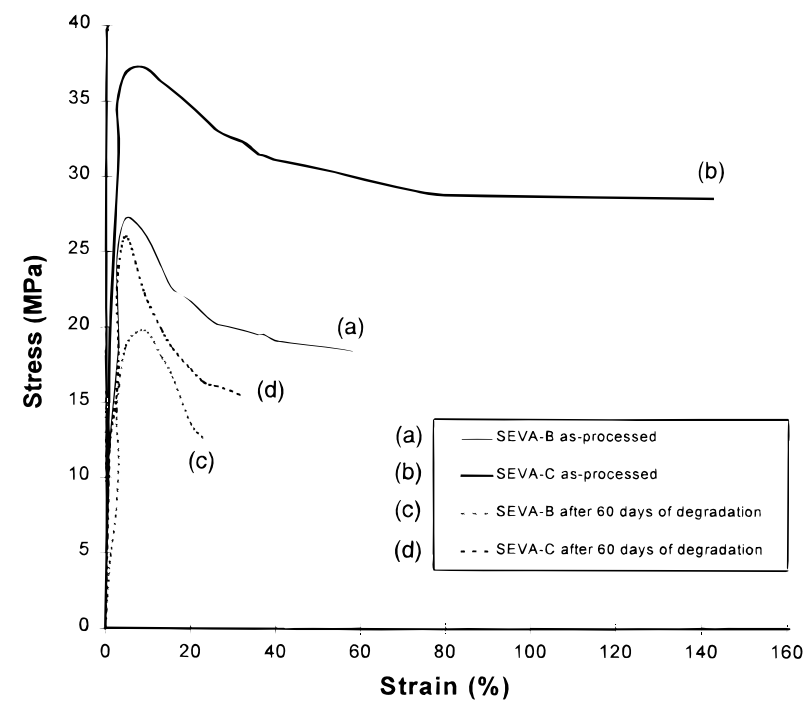

Fig. 4. Typical stress vs. strain curves for SEVA-C and SEVA-B before degradation (as-processed), and after 60 days of degradation in HBSS

also studied and it was found that the BS concentration has almost no effect within the test time. The faster degradation rate in solutions containing bovine serum was to be expected, as these blends are susceptible to enzymatic degradation. ${ }^{10,18}$

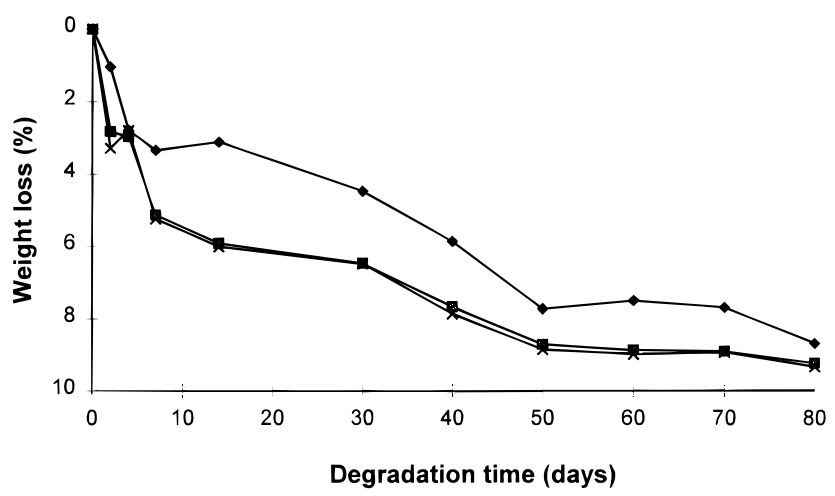

Fig. 5. Dry weight loss of SEVA-C in: $(\bullet)$ HBSS; $(\square)$ HBSS with $10 \%$ bovine serum; $(\times)$ HBSS with $30 \%$ bovine serum.

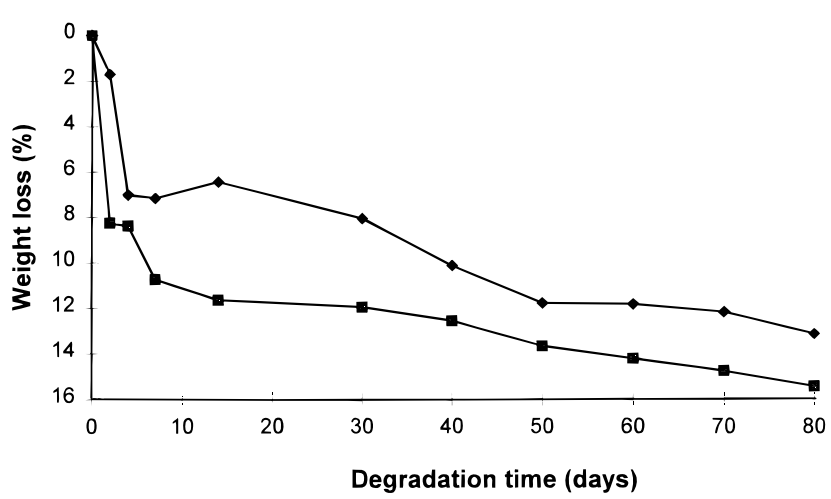

Fig. 6. Dry weight loss of SEVA-B in: $(\bullet)$ HBSS; ( $\square)$ HBSS with $10 \%$ bovine serum

POLYMER INTERNATIONAL VOL. 43, NO. 4, 1997 
In fact, when bovine serum is added, there is an initial increase in degradation rate, which is attributed to the more rapid start of leaching of the molecular chains to the solution. However, the degradation rate does not increase further with time, and after 50 days of immersion the weight loss tends to stabilise. Further degradation tests are in progress, with and without renewal of the degradation media, in order to identify the influence of any concentration gradient effect on the reported results. The measured weight losses are greater than in similar tests carried out using standard HBSS, and support the expectation of the occurrence of a different degradation mechanism in an enzymatic environment. These results are preliminary and much further data, relating to longer degradation times, are needed to draw firmer conclusions.

Figures 7 and 8 show, respectively, SEM micrographs of SEVA-A and SEVA-C tensile test fracture surfaces, produced before and after 60 days of degradation in HBSS. The micrographs indicate the loss of material and the structural changes that result from ageing in the physiological media. It is clear from the figures that the morphology of the mouldings produced with both
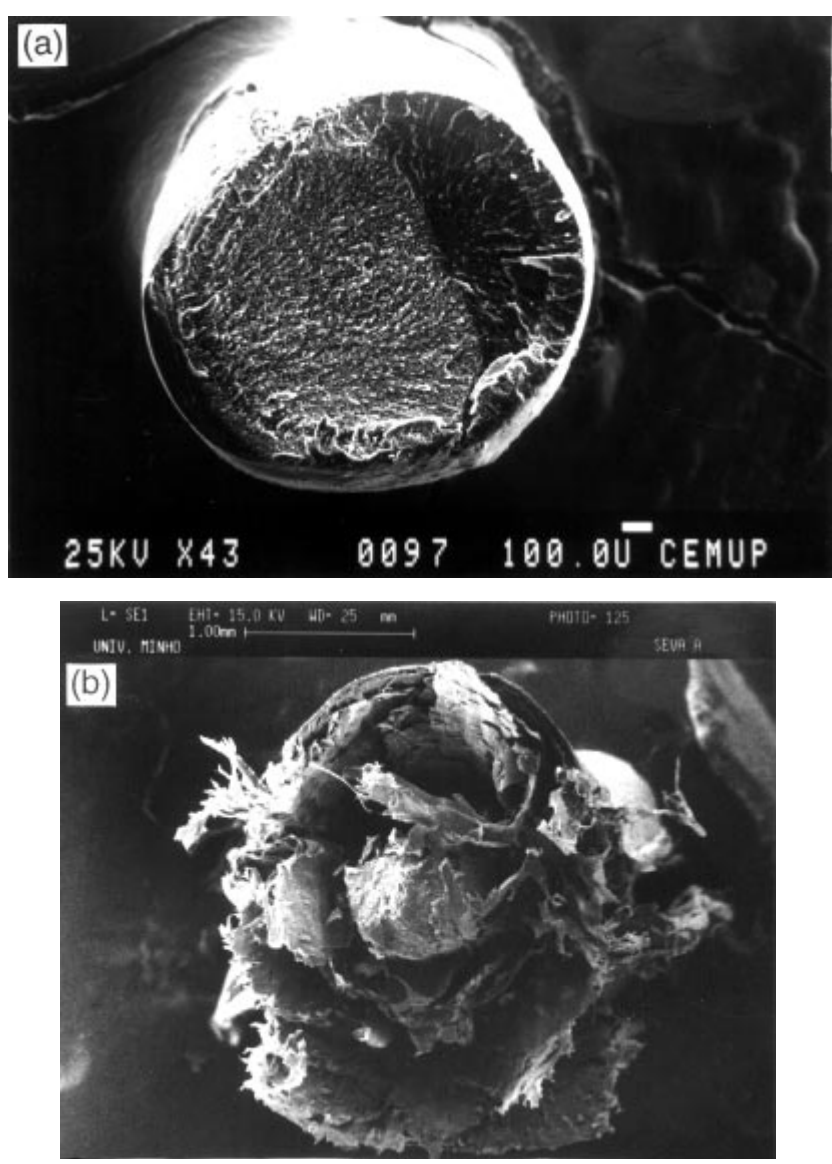

Fig. 7. SEM micrographs of tensile fracture surfaces for: (a) as-processed SEVA-A; (b) SEVA-A after 60 days of degradation in HBSS.
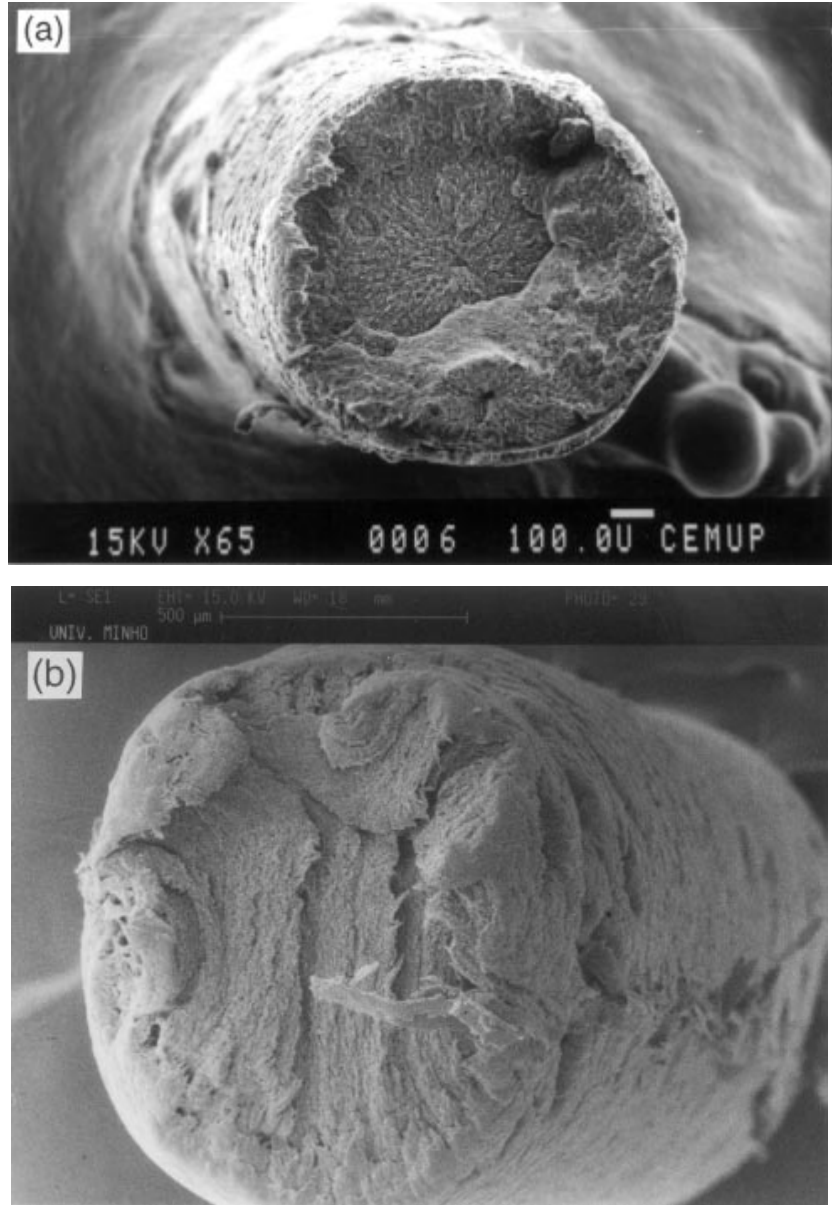

Fig. 8. SEM micrographs of tensile fracture surfaces for: (a) as-processed SEVA-C; (b) SEVA-C after 60 days of degradation in HBSS.

blends was substantially affected by the ageing in HBSS. However, as already discussed, it is evident that more rapid degradation and greater loss in weight occurred in the SEVA-A sample.

Tables 5 presents the mechanical properties of SEVA-C after sterilisation in EtO, and relates to one and two sterilisation cycles. EtO sterilisation results in some degradation of the mechanical properties, though after one sterilisation cycle the SEVA-C modulus decreased by only about $9 \%$. After two cycles, there was a deep amorphitisation of the polymer structure as

TABLE 5. Mechanical properties of conventionally injection-moulded ( $\phi 1.5 \mathrm{~mm}$ samples) SEVA-C after one and two sterilisation cycles in EtO

\begin{tabular}{lccr}
\hline $\begin{array}{c}\text { Material } \\
\text { condition }\end{array}$ & $\begin{array}{c}E_{1 \%} \\
(\mathrm{GPa})\end{array}$ & $\begin{array}{c}\text { UTS } \\
(\mathrm{MPa})\end{array}$ & \multicolumn{1}{c}{$\begin{array}{c}\boldsymbol{\varepsilon}_{\mathrm{r}} \\
(\%)\end{array}$} \\
\hline As processed & 1.95 & 34.9 & 142.6 \\
After 1 cycle & 1.77 & 45.6 & 40.9 \\
After 2 cycles & 1.39 & 46.1 & 40.8 \\
\hline
\end{tabular}




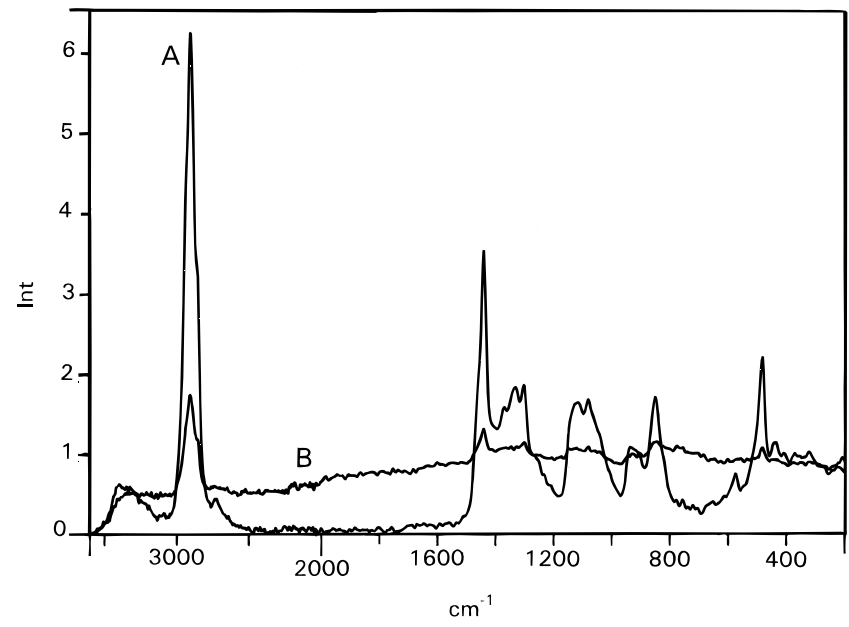

Fig. 9. Raman spectra of SEVA-C: (A) as-processed; (B) asprocessed and after two sterilisation cycles.

detected by Raman spectroscopy (Fig. 9), which resulted in a final modulus of only $1.39 \mathrm{GPa}$, representing a loss of $29 \%$. The sterilisations were carried out using an industrial autoclave according to standard company practice. Further research should lead to the establishment of optimum sterilisation procedures (considering alternatives such as $\gamma$-radiation or plasmabased methods) and operating parameters for SEVA blends.

\section{CONCLUSIONS}

The mechanical properties and the degradation behaviour of the SEVA blends make them good candidates for use as biomaterials. By changing the grades and optimising the processing parameters it may be possible to attain very distinct properties that provide for several different applications.

The three starch/EVOH blends exhibit very different mechanical performance. By using the shear controlled orientation in injection moulding (Scorim) technique it was possible to induce anisotropy into the mouldings and to obtain simultaneously enhanced values of stiffness and ductility.

The degradation behaviour in HBSS also proved to be strongly dependent on the SEVA grade and, further- more, on the addition of proteins, which tended to increase degradation rates.

Finally, it was observed that the SEVA polymers could be subjected to one EtO sterilisation cycle without substantial loss of properties, but two consecutive cycles strongly degraded the polymer structure and mechanical properties.

\section{ACKNOWLEDGEMENTS}

Rui L. Reis wishes to acknowledge Programme PRAXIS XXI for a research grant that supports his work in the UK. We are also very grateful to Novamont, Italy, for supplying the blends used in this research and to Pronefro, Portugal for performing the sterilisations.

\section{REFERENCES}

1 Hayashi, T., Prog. Polym. Sci., 19 (1994) 663.

2 Daniels, A. U., Andriano, K. P., Smutz, W. P., Chang, M. K. O. \& Heller, J., J. Appl. Biomater., 5 (1994) 51.

3 Andriano, K. P., Pohjonen, T. \& Tormalla, P., J. Appl. Biomater., 5 (1994) 133

4 Knowles, J. C. \& Hastings, G. W., J. Mater. Sci.: Mater. Med., 3 (1992) 352.

5 Rokkanen, P. U., Ann. Med., 23 (1991) 109.

6 Reis, R. L. \& Cunha, A. M., J. Mater. Sci.: Mater. Med., 6 (1995) 786.

7 Reis, R. L., Cunha, A. M., Allan, P. S. \& Bevis, M. J., J. Polym. Advanced Techniques 7 (1996) 784

8 Bastioli, C., Bellotti, V., Del Giudice, L. \& Lombi, R., PCT Int. Pat. Appl., WO91/02025 (1991).

9 Bhattarcharya, M., Vaidya, U. R., Zhang, D. \& Narayan, R., J. Appl. Polym. Sci., 57 (1995) 539.

10 Bastioli, C., Bellotti, V., Del Guidice, L. \& Gilli, G., J. Environ Polym. Degrad., 1 (1993) 181.

11 Bastioli, C., Bellotti, V. \& Rallis, A., Rheol. Acta., 33 (1994) 307.

12 Griffin, G. J. L., Polym. Degrad. Stabil., 45 (1994) 241.

13 Ogbona, G. I., Kalay, G., Allan, P. S. \& Bevis, M. J., J. Appl. Polym. Sci., 58 (1995) 213.

14 Allan, P. S. \& Bevis, M. J., Br. Pat., 2170-140-B (1987).

15 Allan, P. S. \& Bevis, M. J., Plast. Rubb. Process. Applic., 7 (1987) 3.

16 Allan, P. S. \& Bevis, M. J., Comp. Manuf., 2 (1990) 79.

17 Reis, R. L., Cunha, A. M., Allan, P. S. \& Bevis, M. J., in Polymers in Medicine and Surgery, eds J. Courtney et al. Institute of Materials, London, 1996, p. 195.

18 Bastioli, C., Bellotti, V., Camia, M., Del Giudice, L. \& Rallis, A., Biodegradable Plastics and Polymers, eds Y. Doi and K. Fukuda. Elsevier, Amsterdam, 1994, p. 200. 